\title{
INDUSTRIALISMO EM ESCALA ECONÔMICA
}

\author{
J. Petrelli Gastaldi \\ Professor de Economia Política da Fa- \\ culdade de Direito da Universidade do \\ Paraná.
}

A maior preocupação do analista, ao pretender-se maior irradiação ou propulsão em determinada área geo-econômica, será a de investigar se a produção industrial pode ser realizada em escala econômica, isto é, se os produtos obtidos conterão, ou não, um teor de propulsão da atividade econômica nacional. A essa fôrça de propulsão denomina-se - poder de irradiação da produtividade.

Daí a importância de que se revestem as denominadas indústrias de base, sabido que "a indústria de base é aquela cujo serviço ou produto serve de veículo à melhoria da produtividade às demais produções. É de base porque êsse produto é um elemento precípuo de aperfeiçoamento da produção para as demais atividades econômicas" (1).

Portanto, para as economias sub-desenvolvidas, existe o problema originário da instalação em escala de preço módico, das indústrias de base, notadamente as de combustíveis e de produtos metalúrgicos. Referidas indústrias são altamente propulsoras do parque fabril. Possuem efeito multiplicador e favorável ao desenvolvimento econômico, porquanto incentivam o surgimento das indústrias subsidiárias.

(1) - Octavio Gouveia de Buthōes, "As Condiçŏes Econômicas para a Expansão das Indústrias de Base", in Rev. do Conselho Nacional de Economia, n.॰ 34 , pg. 56. 
O ideal, em tal setor, é a possibilidade da utilização máxima de matéria-prima nacional, a existência de um ponderável mercado consumidor interno, e, "que a exploração de uma soma de matérias-primas regionais possa, assim, ser despertada. Além disso, divisas obtidas pela exportação do produto industrial podem efetivar novas inversões, que, em regra, se destinam à própria região", conforme conclui brilhante análise do Conselho Nacional de Economia, contida em parecer emitido a respeito da instalação de uma indústria de alumínio, com o aproveitamento da energia do rio São Fran$\operatorname{cisco}^{(2)}$.

Abordamos o problema das indústrias de base apenas para caracterizarmos a necessidade das mesmas, imprescindíveis para acelerar o desenvolvimento, como necessárias para abrir à iniciativa privada novos campos para a expansão das indústrias de bens de consumo em bases racionais de atividade.

Porém, no pressuposto de que determinada região geoeconômica já conte com tais indústrias básicas (e o Brasil as possui em certas áreas), o que nos interessa é saber se as indústrias correlatas ou decorrentes daquelas possuem teor econômico, isto é, se estarão aptas a produzir em escala econômica. Tal investigação não será supérflua, sabido que três quartas partes da renda nacional brasileira já decorrem de atividade não agrícola. A renda nacional, conforme dados do IBGE, ascendeu a 750 bilhões de cruzeiros em 1956, sendo que a contribuição do setor agrícola, ou, mais precisamente agropecuário, não foi além de 200 bilhões.

Os últimos inquéritos têm demonstrado que a estrutura dos custos de produção, notadamente dos industriais, vem denotando um sensível desequilíbrio na proporcionalidade dos seus componentes, com reflexos inevitáveis não apenas sôbre os preços e a procura, mas, também, sôbre a produtividade em geral. Infelizmente, grande parte dos industriais ainda não se apercebeu da suma relevância do problema denominado "apuração do custo". Muitas vêzes uma determinada emprêsa, sem o perceber, estará produzindo em escala não eco-

(2) - Parecer do Conselho Nacional de Economia, "Indústria de Reduçáo de M1nério e Fabricaçäo de Lingotes de Alumínio", Rev. C.N.E., n. ${ }^{\circ} 34$, pg. 23. 
nômica, isto é, sem possibilidade de cobrir, com o preço de venda, a remuneração dos fatores integrantes do processo produtivo. Quando tal ocorre, o preço de aquisição estará em discordância com os gastos de fabricação, sendo fatal a ruína econômica e financeira da emprêsa, embora em espaço de tempo variável.

Como é óbvio, a importância de que se reveste a eficiência da apropriação do custo de produção, não diz respeito apenas às atividades industriais. A racionalização da organização administrativa deve abranger, também, a produção agro-pecuária, como a de serviços e de transportes. A gravosidade crescente dos nossos principais produtos primários café, cacau, pinho e mate - frente a similares de outras áreas, é, em grande parte, uma conseqüência do empirismo da nossa produção agrícola ou extrativa. Não basta apenas agressividade para a conquista dos mercados mundiais; impõe-se a produção a preços justos e remuneratórios, com mútua compensação aos consumidores e produtores.

Não será possível cogitar-se de desenvolvimento econômico, persistindo a nossa economia apegada a métodos rotineiros, cada vez mais distanciada da organização científica da moderna produção. Não existindo essa preocupação de planejamento e contrôle, iremos deparar, inapelàvelmente, com o perigo sempre mais iminente da ruína econômica; e, enquanto esta não eclodir, com o sacrifício do consumidor nacional, notadamente se a atividade industrial fôr protegida pelas barreiras aduaneiras. Um país cuja indústria procura proteger-se da concorrência estrangeira por perene protecionismo estatal, jamais poderá atingir um verdadeiro desenvolvimento econômico. Uma indústria, nessas condições, jamais será emancipada. A consolidação industrial não pode decorrer de permanente protecionismo, representado por barreiras alfandegárias e contrôle cambial, embora tais medidas possam ser (e geralmente o são) necessárias para o impulso inicial da atividade de transformação.

O barateamento da produção em escala de massa, com a auto-limitação dos lucros percentuais (a ser compensada pelo volume de fabricação), deve ser o roteiro forçado para a obtenção do pleno desenvolvimento. Uma indústria com tais 
fundamentos, conhecendo a fundo a própria estrutura do seu custo, estará apta para atravessar a barreira do protecionismo. Sòmente dêsse modo ser-lhe-á possível atingir a maioridade, sem receios de futura concorrência estrangeira, dentro de um regime de livre comércio, aliás rigorosamente conforme com os princípios de F. LIST.

Para tanto, porém, necessário se torna uma estrutura empresarial administrativamente científica, aliada à uma organização também científica da produção, de modo a possibilitar o barateamento dos produtos. Sabemos que a tendência ascendente dos preços, em qualquer economia - salvo condições temporárias e artificiais - é decorrência direta dos custos, cuja estrutura está a merecer melhor atenção de parte das organizações econômicas. Entre nós já existem alguns trabalhos de pesquisa em tal sentido. O IBGE procedeu inquéritos a respeito. A análise dos resultados obtidos em cêrca de 100 municípios, dos mais desenvolvidos do país, indica resultados dos mais sintomáticos, servindo como ponto de referência para a conjuntura inflacionária no triênio 1955$1957^{(3)}$.

Tais "Inquéritos Econômicos" demonstram, por exemplo, que os salários, nesses 100 municípios, têm aumentado em índice inferior ao dos preços dos produtos. $O$ inverso ocorre com os gastos com matérias-primas, energia elétrica e combustíveis, que encarecem muito mais ràpidamente. $\mathrm{O}$ produto-hora, ou seja o valor da produção por operário, no curso de uma hora, elevou-se de Cr\$124,30 em 1955, para Cr\$194,00 em 1957. O salário-hora evoluiu, entre aquêles anos extremos, de Cr\$14,77 para Cr\$22,43. Porém, os gastos com matérias-primas, combustíveis e energia elétrica, ascenderam (1955-57) respectivamente de $\mathrm{Cr} \$ 58,19$ para $\operatorname{Cr} \$ 91,60$; de Cr\$ 17,14 para $\operatorname{Cr} \$ 41,69$ e de $C r \$ 8,92$ para 16,40 . Percebemos, assim, que, enquanto o incremento do produto-hora foi de $56,1 \%$ o do salário foi de $51,9 \%$; porém, o das matériasprimas atingiu a $57,4 \%$, o dos combustíveis $143,2 \%$ e o de energia elétrica $83,9 \%$. Temos, portanto, que em 1955 cada 100 cruzeiros de produto representava $\mathrm{Cr} \$ 11,90$ de salários, Cr\$ 46,80 de matérias-primas, Cr\$ 13,80 de combustíveis e Cr\$ 7,20 de energia elétrica. Em 1957 a participação de cada

(3) - "Inquéritos Econômicos", IBGE, 1959. 
um dos componentes citados passou a ser a seguinte: salários (Cr\$ 11,60); matérias-primas (Cr\$ 47,20); combustíveis (Cr\$ $21,50)$ e energia elétrica (Cr\$ 8,50), por 100 cruzeiros de produto. Dêsse modo, percebe-se a diminuição da compensação pelo trabalho, do mesmo modo que o rédito empresarial também diminuiu de $20,3 \%$ em 1955, para $11,2 \%$ em 1957. E tal resultado, na verdade, não representa o rédito real da emprêsa, pois não computamos, naquele custo, os gastos com amortização, depreciação e substituição de maquinaria, juros do capital, fundos de indenização, encargos fiscais, etc.

Conseqüentemente, a medida que decresce o poder aquisitivo de ponderável parcela da massa consumidora, também a rentabilidade da emprêsa vai diminuindo, em evidente processo de descapitalização, sumamente grave numa economia inflacionária, sabendo-se quão íntimas são as relações entre a inflação e o nível geral dos preços.

Produzir em escala econômica, portanto, significa a obtenção de rentabilidade, deduzido o custo de produção, de modo a permitir-se não apenas a continuidade do empreendimento, como a justa remuneração dos empreendedores capitalistas.

A crescente elevação dos índices de custos na produção nacional, mais fàcilmente verificáveis no ramo industrial, tem determinado um fenômeno interessante: o faturamento total anual, nas principais indústrias, tem aumentado sensìvelmente. Mas, tal aumento não resulta de acréscimo das unidades produzidas e sim do valor comercial da mesma mercadoria. As emprêsas, por decorrência do agravamento dos custos, necessitam dispor, sempre mais, de maior volume de capital em giro, notadamente para ocorrer às elevações dos preços de matérias-primas e de combustível. Nessas condições, maiores lucros (em têrmos de moeda corrente), porventura acusados pelos balanços, significam, em última análise, uma fórmula de compensação para a descapitalização imposta pelo poder aquisitivo da moeda.

Tais ocorrências são mais comuns nas áreas de economia subdesenvolvida, quando, no dizer de WOLF, "a incerteza ligada aos riscos nos negócios tende a ser elevada".

A produtividade anti-econômica, conforme ficou anterior- 
mente acentuado, não é própria ou exclusiva do setor industrial. A produção em escala não econômica é já bastante acentuada também na agricultura nacional, conseqüência do assustador declínio da fertilidade natural do nosso solo. A queda do rendimento médio por unidade de área é verdadeiramente alarmante no Brasil, colocando-nos em situação vexatória perante os índices de rendimento agrícola nas principais nações. No Diário do Congresso Nacional de 17 de junho de 1959 (pág. 3.119), vamos encontrar dados estatísticos, comprobatórios dos baixos rendimentos agrícolas nacionais. A cultura da cana produz, no Brasil, por hectare plantado, 36,2 quintais, enquanto na Oceania o rendimento por hectare é de 76,5 quintais, no Egito 71,1 quintais, na Colômbia 45,7 quintais. Para a cultura do milho, o rendimento médio, por hectare, entre nós, é de 13,2 quintais. Na Argentina o rendimento é de 24,4 quintais, nos Estados Unidos de 18,00 quintais e na China de 13,5 quintais. A cultura do fumo, para igual unidade de área, produz um rendimento médio, no Brasil, de 6,8 quintais, sendo de 19,3 quintais no Paraguai, 12,8 quintais no Chile, 11,00 quintais na China e 17,9 quintais na França. A cultura do algodão, por hectare, produz no Brasil um rendimento médio de 1,4 quintais. No Egito o rendimento médio é de 5,4 quintais, nos Estados Unidos de 3,00 e na China de 2,1 quintais.

Estatísticas mais recentes concluem que o Brasil, para igual área plantada, colhe apenas $38,75 \%$ da produção obtida pelos países mais adiantados, ao passo que, ao inverso, os países mais adiantados, no mesmo setor, colhem, na mesma área plantada, $262,5 \%$ a mais, ou seja, duas e vêzes e meia maior que a do Brasil.

Embora para o setor agrícola a ausência de uma contabilidade regular nos prive de um conhecimento mais exato da respectiva estrutura de custo, é óbvio que diferentes condições negativas coincidem para a baixa da sua rentabilidade. A deficiência dos meios de transporte, a erosão, a necessidade de corretivos para o solo, a escassez de maquinaria, tudo se conjuga para tornar a produção agrícola cada vez menos econômica, desestimulando investimentos e mais, agravando a inflação, pela necessidade de socorrer-se, através de subsídios, a mesma atividade. 